\title{
A CONSENSUALIDADE ADMINISTRATIVA E A ELABORAÇÃO DE PROTOCOLOS CLÍNICOS E DIRETRIZES TERAPÊUTICAS NO ÂABITO DO SISTEMA ÚNICO DE SAÚDE
}

\begin{abstract}
THE ADMINISTRATIVE CONSENSUALITY AND THE PREPARATION OF CLINICAL PROTOCOLS AND THERAPEUTIC GUIDELINES WITHIN THE FRAMEWORK OF THE PUBLIC HEALTH SYSTEM
\end{abstract}

\author{
${ }^{1}$ Clarissa Sampaio Silva
}

\section{RESUMO}

O presente artigo trata da necessidade de a Administração Pública resgatar seus espaços de decisão no tocante à concretização do direito à saúde, como contraponto à excessiva judicialização. Com base em pesquisa doutrinária e legislativa procura-se demonstrar que a consensualidade, nova vertente da atuação administrativa, possui importância para a elaboração, no âmbito do Sistema Único de Saúde, de consensos médico científicos, cuja observância é recomendada em enunciados do Conselho Nacional de Justiça. O incremento da participação social na aprovação daquelas pautas e a abertura de dialógos institucionais para discussão de determinados casos pode reduzir recursos ao Poder Judiciário

Palavras-Chave: Sistema Único de Saúde. Consensualidade. Protocolos

\begin{abstract}
This article deals with the need for the Public Administration rescue his decision spaces in relation to the realization of the right to health, as opposed to excessive judicialization. Based on doctrinal and legislative research seeks to demonstrate that the consensuality, new aspects of administrative action, has importance for the development, under the Public Health System, scientific medical consensus, which recommended observance in statements of the National Justice Council . The increase of social participation in the adoption of those guidelines and the opening of institutional dialogue to discuss certain cases can reduce recourse to the courts.
\end{abstract}

Keywords: Public Health System. Consensuality.Guidelines

\footnotetext{
${ }^{1}$ Doutora em Direito pela Universidade de Lisboa, (Portugal). Professora da Universidade de Fortaleza - Unifor, Fortaleza, Ceará, (Brasil). E-mail: sampaioclarissa@ hotmail.com
} 


\section{INTRODUÇÃO}

A judicialização da saúde, fenômeno causador de profundos impactos nas políticas públicas desenvolvidas por União, Estados e Municípios no âmbito do Sistema Único de SaúdeSUS, traz consigo a reflexão sobre a necessidade de a Administração Pública resgatar seus espaços próprios de decisão, e que vêm sendo ocupados pelo Poder Judiciário.

O reforço da legitimação da instância administrativa para definir, além das políticas públicas, aquilo que possa ser fornecido de forma universal, segura, eficaz e com adequada relação custo benefício pelo sistema público de saúde passa pela incorporação, ao processo de realização das escolhas terapêuticas realizadas em tal âmbito, da nova vertente de atuação da Administração Pública, marcada pela busca de consensualidade.

A compreensão da atuação administrativa dentro da ordem constitucional de um Estado Democrático de Direito, comprometida, por sua vez, com o respeito e a realização dos direitos fundamentais demanda modificações em concepções e institutos clássicos do Direito Administrativo, levando ao desenvolvimento de novas pautas e formas de atuar que não seguem apenas o tradicional viés unilateral e autoritário, mas que clamam a participação dos cidadãos e da sociedade civil nos processos de tomada de decisões da Administração Pública, bem como o desenvolvimento de outras formas de resolução de conflitos nos quais ela esteja presente.

O presente trabalho pretende situar a elaboração e a aprovação dos Protocolos Clínicos e Diretrizes Terapêuticas pelo Comissão Nacional de Incorporação de Tecnologias, órgão do Ministério da Saúde, no contexto da consensualidade administrativa, de modo a analisar como as vertentes de tal forma de atuação fazem-se aqui presentes, com a apresentação de sugestões para incrementá-las. Trata-se, por sua vez, de pesquisa qualitativa, dentro da procura de novos caminhos de resolução de conflitos na área da saúde.

Para tanto, será feita uma abordagem doutrinária a propósito da consensualidade administrativa, bem como de suas manifestações em diversos setores de atuação da Administração Pública, por meio de pesquisa na legislação, de modo a evidenciar a tendência de recurso a ela, inclusive em áreas tradicionalmente infensas a uma alteração de perspectivas e de instrumentos de ação.

Passa-se, a seguir, à análise da função dos Protocolos Clínicos e Diretrizes Terapêuticas, no contexto da dimensão objetiva do direito fundamental à saúde, com base na doutrina, na legislação de regência, como também, nos entendimentos emitidos pelo Conselho 
Nacional de Justiça, sob a forma de enunciados. A pesquisa estende-se ao processo administrativo concernente à aprovação dos protocolos e diretrizes, para, por fim, verificar não apenas a manifestação da vertente da consensualidade, como, também, a busca de formas de seu incremento.

\section{A CONSENSUALIDADE COMO NOVA VERTENTE DE ATUAÇÃO DA ADMINISTRAÇÃO PÚBLICA}

A atuação da Administração Pública no âmbito de um Estado Democrático de Direito e submetida aos princípios do art.37 da Constituição Federal de 1988 demanda o desenvolvimento de novas pautas e formas de proceder que espelhem os valores que lhes são decorrentes.

Aliam-se a tal a perspectiva os deveres de sua proteção e concretização dos direitos fundamentais por parte da Administração Pública, dotados, por sua vez, de centralidade na ordem jurídica. Diante deles, os esquemas clássicos do Direito Administrativo como a legalidade estrita, as técnicas unilaterais e autoritárias de atuação falham em oferecer respostas adequadas aos seus conflitos.

Semelhantes fatores têm levado a uma necessidade de releitura de institutos tradicionais do Direito Administrativo, como o interesse público, o poder de polícia e o serviço público, à luz da Constituição e dos direitos fundamentais, consoante destaca, na doutrina brasileira, BINENBOJM (2006), quedando a atividade administrativa por eles impregnada.

Como consequências podem ser citadas mudanças paradigmáticas no Direito Administrativo no tocante à forma de atuação estatal, a saber: a) a reformulação das características tradicionais do ato administrativo e o abandono da centralidade da sua figura, o qual passa a ser ladeado pelo procedimento administrativo e pela relação jurídica, levando à uma procedimentalização e à uma visão mais ampla do atuar da Administração Pública, que não se esgota na pontualidade do ato, tal como destaca, na doutrina portuguesa, PEREIRA DA SILVA (1999); b) a contratualização e utilização de algumas formas de Direito Privado ESTORNINHO (1999), e mais, recentemente, a busca de uma consensualidade na sua atuação.

Com efeito, o caráter pluralista de uma sociedade aberta, com suas demandas de naturezas diversas e várias formas de realização, tem levado a Administração Pública a 
desenvolver, ao lado de suas formas clássicas de atuação, o que se tem chamado de "atuação soberana consensual", tal como descreve ESTORNINHO (1994:44):

“Assim, ao lado da atuação tipicamente soberana, que autoriza ou impõe unilateralmente, apareceu essa nova figura dogmática da atuação soberana consensual. Trata-se de uma forma de administração nova, negociada ou contratual, em que o acordo vem substituir os tradicionais atos unilaterais de autoridade, aparecendo em relação a eles como uma verdadeira alternativa, e em que os administrados deixam de ser meros destinatários passivos das decisões unilaterais da Administração Pública.”

A admissão da consensualidade, por sua vez, requer a redefinição de outros dogmas clássicos do Direito, representados pelo princípio da supremacia do interesse público sobre o privado, bem com a sua indisponibilidade, devidamente descritos por MELLO (2005 ).

O interesse público, considerando a inserção constitucional da Administração Pública, em especial sua vinculação aos princípios e direitos fundamentais, não constitui algo abstrato ou uma fórmula que possa ser preenchida com qualquer conteúdo. Ter-se-á, assim, dentro da presente abordagem, ora uma convergência entre interesse público e direitos fundamentais, ora, na hipótese da configuração de verdadeiros conflitos com eles, a necessidade de recurso à ponderação, tal como explica SARMENTO (2006 ).

Quanto à indisponibilidade do interesse público, se é certo que a Administração Pública não pode optar por buscar sua realização ou não, uma vez que a ordem jurídica constitucional impõe a ela desideratos que devem ser atingidos, assegurando-lhe para tanto, prerrogativas públicas, não é menos certo que elas devem ser compreendidas como instrumentos de atuação estatal, e não como fins em si mesmas.

O exercício dos poderes de autoridade, tidos como próprios do regime jurídico administrativo, dentro da doutrina clássica do Direito Administrativo, autoriza determinadas medidas que implicam, nas palavras de MELLO (2005, p.59),“a possibilidade, em favor da Administração, de constituir os privados em obrigações, por meio de ato unilateral daquela. Implica, outrossim, muitas vezes, o direito de modificar, também unilateralmente, relações já estabelecidas".

Como exemplos, pode ser citado o exercício do poder de polícia, autoexecutório em várias situações, a desapropriação e requisição de bens, a alteração ou rescisão unilateral de contratos administrativos, a modificação, igualmente unilateral, do regime jurídico dos servidores públicos. 
Todavia, as prerrogativas públicas, os poderes de autoridade possuem a nota de instrumentalidade, ou seja, servem para assegurar a realização do interesse público, de modo que se a suspensão ou o momentâneo recolhimento delas contribuir para o seu alcance, o ordenamento jurídico deve contemplar hipótese e meios para que a Administração Pública encontre soluções consensuais, sendo esta, decerto a nova vertente de sua atuação.

Como fatores de fortalecimento da busca pela consensualidade são apontadas pela doutrina brasileira: a democracia substantiva, a contratualização e o reclame pela eficiência, dentro da perspectiva de que as decisões concertadas possuem, naturalmente, maior legitimidade do que aquelas impostas, segundo DE PALMA (2010)

Com efeito, a participação do cidadão na formação da vontade estatal representa forma de densificação do princípio democrático, segundo NETTO (2012), não devendo restringir-se aquela ao exercício do sufrágio, mas fazer-se presente na tomada de decisões sobre os assuntos de maior interesse da coletividade, as quais devem incorporar as contribuições de setores representativos da sociedade civil, de modo a atender interesses aos mesmo tempo plúrimos e cambiantes, reflexos de uma "modernidade líquida", muito bem descrita por BAUMAN (2003, p.7).

Deve-se ainda considerar que a participação e a colaboração dos cidadãos e da sociedade civil na tomada de decisões estatais representa manifestação, dentro da teoria dos status ensejados pelos direitos fundamentais, segundo Jellinek, o status ativo, e que, de forma atualizada, engloba, também, o status ativusprocessualis proposto por Haberle ou seja, o direito à organização e ao procedimento, condições necessárias para a realização dos direitos fundamentais, consoante leciona SARLET ( 2003 ).

Na doutrina brasileira, segundo DE PALMA (2010), a consensualidade é concebida sob duas perspectivas, a saber: a) como forma de participação na Administração Pública ou no exercício da função pública; b) como celebração de acordos entre a Administração Pública e particulares para fins de resolução consensual de dado conflito.

Enquanto que, sob a primeira perspectiva, tem-se a abertura do processo de tomada de decisões para incorporação dos posicionamentos dos cidadãos ou de setores da sociedade civil, sob a última perspectiva, a Administração suspende ou coloca de lado as prerrogativas públicas para o fim de possibilitar uma composição harmoniosa de dada situação conflitiva. Ou seja, em princípio será objeto da concertação o exercício de poderes de autoridade, das prerrogativas públicas, quando tal medida constituir a forma de realização do interesse público. 
Com efeito, nas mais variadas áreas vem se consolidando a adoção de técnicas e instrumentos volvidos à busca da consensualidade administrativa, tanto judicial quanto extrajudicialmente. Como exemplos, podem ser citados os Termos de Ajustamento de CondutaTACs, previstos na Lei da Ação Civil Pública ( Lei n. 7347/85, em seu art. $5^{\circ} \S 6$ ) ${ }^{2}$, na Lei 12.249/2010, em seu art. $4^{\circ}-\mathrm{A}$, no tocante à União, suas autarquias e fundações e, mais recentemente, a Lei n. 13.140/2015, que dispõe sobre a mediação entre particulares e a autocomposição de conflitos no âmbito da Administração Pública, em seu art.32, III $\S 3^{\mathrm{o} 3}$, e que fomenta a tentativa de prevenção resolução deles por meio de câmaras a serem instauradas nos órgão da Advocacia Pública, de modo a procurar reverter os elevadíssimos índices de litigiosidade contra o Poder Público.

Outro instrumento importante é o Termo de Compromisso, previsto no art. 627-A ${ }^{4}$ da Consolidação das Leis do Trabalho, e que, em determinadas situações de descumprimento da legislação trabalhista, permite a suspensão da aplicação das penalidades administrativas, com vistas a dar oportunidade para que o empregador se adeque às exigências normativas, adotando, ao fim, as medidas que a Fiscalização do Trabalho almeja. Tem-se, aqui, a busca de concertação em atividade tipicamente autoritária, qual seja, o exercício do Poder de Polícia.

Os ventos da consensualidade atingem, também, área tradicionalmente imune à concertação, qual seja, a função pública, em que a natureza estatutária, institucional do regime faz com que os direitos e obrigações dos servidores públicos sejam estabelecidos e alterados unilateralmente por lei. Ocorre que o Brasil ratificou a Convenção 151 da Organização

\footnotetext{
${ }^{2} \S 6^{\circ}$ “Os órgãos públicos legitimados poderão tomar dos interessados compromisso de ajustamento de sua conduta às exigências legais, mediante combinações, que terá eficácia de título executivo extrajudicial."

${ }^{3}$ Art. 32. A União, os Estados, o Distrito Federal e os Municípios poderão criar câmaras de prevenção e resolução administrativa de conflitos, no âmbito dos respectivos órgãos da Advocacia Pública, onde houver, com competência para:

I - dirimir conflitos entre órgãos e entidades da administração pública;

II - avaliar a admissibilidade dos pedidos de resolução de conflitos, por meio de composição, no caso de controvérsia entre particular e pessoa jurídica de direito público;

III - promover, quando couber, a celebração de termo de ajustamento de conduta.

$\S 1$ o O modo de composição e funcionamento das câmaras de que trata o caput será estabelecido em regulamento de cada ente federado.

$\S 2$ 을 submissão do conflito às câmaras de que trata o caput é facultativa e será cabível apenas nos casos previstos no regulamento do respectivo ente federado.

$\S 3$ - Se houver consenso entre as partes, o acordo será reduzido a termo e constituirá título executivo extrajudicial.

${ }^{4}$ Art. 627-A. Poderá ser instaurado procedimento especial para a ação fiscal, objetivando a orientação sobre o cumprimento das leis de proteção ao trabalho, bem como a prevenção e o saneamento de infrações à legislação mediante Termo de Compromisso, na forma a ser disciplinada no Regulamento da Inspeção do Trabalho. (Incluído pela Medida Provisória ${ }^{\circ} 2.164-41$, de 2001)
} 
Internacional do Trabalho, por meio do Decreto Legislativo n.206, de 07/04/2010 e promulgoua, mediante o Decreto Presidencial no 7.944, de 06/03/2013, trazendo, com elas, questão inovadora para as relações entre Administração Pública e seus servidores, qual seja, a possibilidade de negociação coletiva como forma de estabelecimento de direitos e obrigações dentro do regime funcional.

Por fim, mirando para a vertente da consensualidade de participação do cidadão na tomada de decisões por parte da Administração Pública, importante destacar as Consultas e Audiências Públicas previstas na Lei 9.784/99, em seus arts.31 e 32, respectivamente, podendo as primeiras, a critério do órgão competente, ser abertas, quando se estiver diante de matéria de interesse geral e, as últimas, quando a questão for considerada relevante.

Os exemplos demonstram ser a consensualidade a nova dimensão da atuação administrativa, a qual implica uma verdadeira modificação de "esquemas mentais e dos quadros teóricos tradicionais da Ciência jurídico-administrativa", consoante alerta Estorninho (1999: 45), dentro da perspectiva do "elogio ao consenso", cuja "função primeira é a de evidenciar a consensualidade como instrumento de ação administrativa” DE PALMA ( 2010, p.97).

\subsection{DIREITO FUNDAMENTAL À SAÚDE NO ÂMBITO DO SISTEMA ÚNICO DE SAÚDE: O PAPEL DOS PROTOCOLOS CLÍNICOS E DIRETRIZES TERAPÊUTICAS}

O direito à saúde, na qualidade de direito fundamental (CF, art.196) possui, além da dimensão subjetiva, da qual decorrem direito a prestações por parte do Estado, tendo em vista tratar-se de direito social, uma dimensão objetiva, que vem a assegurar-lhe o status de "elemento fundamental da ordem jurídica da coletividade”, segundo HESSE (1998, p.28).

No âmbito da dimensão objetiva dos direitos fundamentais, encontra-se o direito à organização e ao procedimento, dentro da concepção de que a concretização dos direitos fundamentais depende da existência e funcionamento deles.

Representando tal realidade, na ordem constitucional brasileira, tem-se, nos termos do art. 198 da CF, o Sistema Único de Saúde, "rede regionalizada e hierarquizada de saúde, marcado pela descentralização administrativa, com previsão de competências distintas entre os entes federados, pelo atendimento integral e participação da comunidade, de acordo com os incisos I, II e III do referido dispositivo constitucional. 
Para realizar os objetivos de fornecer tratamentos de saúde que atendam aos reclames da universalidade, eficiência, segurança, universalidade, dentro da realidade orçamentária do Estado, a Administração Pública necessita, logicamente, realizar rigoroso planejamento para definir, em função de dados como o perfil de saúde da população, expectativa de vida, prospecções epidemiológicas e de demais enfermidades, nível de conhecimento médico no momento, as opções terapêuticas que serão ofertadas à coletividade.

Desempenhando a relevantíssima função de definir quais as modalidades de tratamento de saúde encontram-se à disposição para diversas situações têm-se os Protocolos Clínicos e Diretrizes Terapêuticas ${ }^{5}$ aprovadas no âmbito da Comissão de Incorporação de Tecnologias, órgão do Ministério da Saúde. Ressalta-se que a Lei n ${ }^{\circ} 12.401$, de 28 de abril de 2011 cuidou de especificar em que consiste a assistência terapêutica integral no âmbito do SUS, o conteúdo dos PCDTSs e DDTs, os critérios de avaliação dos medicamentos, o procedimento para incorporação, exclusão ou alteração pelo SUS de novos medicamentos, bem como de revisão de protocolos e diretrizes, consoante se pode observar a seguir:

“Art. 19-M. A assistência terapêutica integral a que se refere a alínea $d$ do inciso I do art. $6^{-}$consiste em:

I - dispensação de medicamentos e produtos de interesse para a saúde, cuja prescrição esteja em conformidade com as diretrizes terapêuticas definidas em protocolo clínico para a doença ou o agravo à saúde a ser tratado ou, na falta do protocolo, em conformidade com o disposto no art. 19-P;

II - oferta de procedimentos terapêuticos, em regime domiciliar, ambulatorial e hospitalar, constantes de tabelas elaboradas pelo gestor federal do Sistema Único de Saúde - SUS, realizados no território nacional por serviço próprio.

“Art. 19-O. Os protocolos clínicos e as diretrizes terapêuticas deverão estabelecer os medicamentos ou produtos necessários nas diferentes fases evolutivas da doença ou do agravo à saúde de que tratam, bem como aqueles indicados em casos de perda de eficácia e de surgimento de

\footnotetext{
${ }^{5}$ De acordo com a definição contida no art. 1, III do Decreto n. 7646/2011, protocolo clinico e diretriz terapêutica constitui documento que estabelece critérios para o diagnostico da doença ou do agravo à saúde; o tratamento preconizado, com os medicamentos e demais produtos apropriados, quando couber; as posologias recomendadas; os mecanismos de controle clínico; e o acompanhamento e a verificação dos resultados terapêuticos, a serem seguidos pelos gestores do SUS .Enquanto que as Diretrizes Diagnóstico Terapêuticas referem -se à area de Oncologia, os Protocolos Clínicos dizem respeito às enfermidades das demais áreas.
} 
intolerância ou reação adversa relevante, provocadas pelo medicamento, produto ou procedimento de primeira escolha.

Parágrafo único. Em qualquer caso, os medicamentos ou produtos de que trata o caput deste artigo serão aqueles avaliados quanto à sua eficácia, segurança, efetividade e custo-efetividade para as diferentes fases evolutivas da doença ou do agravo à saúde de que trata o protocolo."

"Art. 19-Q. A incorporação, a exclusão ou a alteração pelo SUS de novos medicamentos, produtos e procedimentos, bem como a constituição ou a alteração de protocolo clínico ou de diretriz terapêutica são atribuições do Ministério da Saúde, assessorado pela Comissão Nacional de Incorporação de Tecnologias no SUS.

“Art. 19-R. A incorporação, a exclusão e a alteração a que se refere o art. 19-Q serão efetuadas mediante a instauração de processo administrativo, a ser concluído em prazo não superior a 180 (cento e oitenta) dias, contado da data em que foi protocolado o pedido, admitida a sua prorrogação por 90 (noventa) dias corridos, quando as circunstâncias exigirem.

$\S 1^{\text {o }}$ O processo de que trata o caput deste artigo observará, no que couber, o disposto na Lei $\mathrm{n}^{\mathrm{0}}$ 9.784, de 29 de janeiro de 1999, e as seguintes determinações especiais:

I - apresentação pelo interessado dos documentos e, se cabível, das amostras de produtos, na forma do regulamento, com informações necessárias para o atendimento do disposto no $§ 2^{\circ}$ do art. 19-Q;

III - realização de consulta pública que inclua a divulgação do parecer emitido pela Comissão Nacional de Incorporação de Tecnologias no SUS;

IV - realização de audiência pública, antes da tomada de decisão, se a relevância da matéria justificar o evento.

Segundo esclarece GADELHA (2013: 371), a "árvore de decisões sobre tecnologias na área da saúde" envolve duas etapas fundamentais, quais sejam, a avaliação e a incorporação sistêmica, de modo que, dentro de um sistema público, seja oferecido não aquilo que está disponível, "mas o que se assume como seguro, eficaz e efetivo e como dever prioritário de disponibilizar. Ainda segundo a autora:

"Os protocolos terapêuticos melhoram a qualidade da atenção prestada aos doentes; orientam uma prescrição segura, eficaz e efetiva; democratizam o conhecimento médico e farmacêutico; fazem a avaliação médica e farmacêutica; aperfeiçoam os processos gerenciais assistenciais; garantem ética e tecnicamente indicação médica; melhoram a qualidade da informação registrada e permitem o acompanhamento de uso e a avaliação de resultados." (2013: 371). 
Por sua vez, um dos claros motivos que levaram à edição de referida lei, foi, sem dúvidas, o fenômeno conhecido como a judicialização da saúde, de forma que, consoante destaca CAÚLA (2012,p.100), os problemas dela decorrentes foram devidamente considerados pelo Congresso Nacional resultando "na estruturação de um processo administrativo adequado de definição de estratégias terapêuticas."

A judicialização da saúde, decorrente de uma explosão de litigiosidade sobre tal matéria, tem implicado a transferência, para o Poder Judiciário, da tomada de decisões sobre tratamentos médicos, cirúrgicos em milhares de ações, tanto individuais quanto ações civis públicas, com inúmeras consequências sobre a definição das políticas públicas da saúde, a alocação de recursos públicos, com as respectivas prioridades, bem como sobre as repartições de competências entre os entes federados, estabelecida pela Lei 8080/90.

Embora não seja objeto do presente artigo, a análise das diversas consequências causadas pela judicialização da saúde, é importante pontuar o papel de racionalização e sistematização desempenhado pelos Protocolos Clínicos e Diretrizes Terapêuticas. Estes elementos se não impedirem o recurso ao Poder Judiciário, podem pelo menos colocar a discussão em outro patamar, qual seja, o da necessidade de sua observância nas decisões por ele proferidas, de modo a que venham a incorporar a definição das diversas modalidades de tratamento definidas pela Administração Pública, recusando a concessão daquelas que estejam foram dos PCDTs e dos DDTs.

Trata-se de importante ressalva à amplitude que vem sendo dada pelo Poder Judiciário ao art.196 da CF (direito à saúde), bem como à assistência da saúde integral, que deve ser compreendida dentro do Sistema Único de Saúde, ou seja, no que tenha sido definido, em seu domínio.

Por tais razões, o Conselho Nacional de Justiça, reconhecendo a necessidade de desenvolvimento de uma "política judiciária para a saúde", de modo a estabelecer novas estratégias para o tratamento de tal tema pelo Poder Judiciário, tal como destacado por ASENSI (2013, p.99) por ocasião das duas Jornadas da Saúde, realizadas nos anos de 2014 e 2015, aprovou os seguintes enunciados:

61- Saúde Pública - Proposta de alteração do enunciado n 4 da I Jornada Os Protocolos Clínicos e Diretrizes Terapêuticas (PCDT) são elementos organizadores da prestação farmacêuticas 4 - Os Protocolos Clínicos e Diretrizes Terapêuticas (PCDT) são elementos organizadores da prestação 
farmacêutica, e não imitadores. Assim, no caso concreto, quando todas as alternativas terapêuticas previstas no respectivo PCDT já tiverem sido esgotadas ou forem inviáveis ao quadro clínico do paciente usuário do SUS, pelo princípio do art. 198, III, da CF, pode ser determinado judicialmente o fornecimento, pelo Sistema Único de Saúde, do fármaco não protocolizado.

12 - A inefetividade do tratamento oferecido pelo SUS, no caso concreto, deve ser demonstrada por relatório médico que a indique e descreva as normas éticas, sanitárias, farmacológicas (princípio ativo segundo a Denominação Comum Brasileira) e que estabeleça o diagnóstico da doença (Classificação Internacional de Doenças), tratamento e periodicidade, medicamentos, doses e fazendo referência ainda sobre a situação do registro na ANVISA (Agência Nacional de Vigilância Sanitária).

14 - Não comprovada a inefetividade ou impropriedade dos medicamentos e tratamentos fornecidos pela rede pública de saúde, deve ser indeferido o pedido não constante das políticas públicas do Sistema Único de Saúde.

Já os novos Enunciados, aprovados em maio de 2015, possuem a seguinte redação:

57 - Saúde Pública - Em processo judicial no qual se pleiteia o fornecimento de medicamento, produto ou procedimento, é recomendável verificar se a questão foi apreciada pela Comissão Nacional de Incorporação de Tecnologias no SUS - CONITEC.

61- Saúde Pública - Proposta de alteração do enunciado ${ }^{\circ} 4$ da I Jornada Os Protocolos Clínicos e Diretrizes Terapêuticas (PCDT) são elementos organizadores da prestação farmacêutica, de insumos e de procedimentos, e não limitadores. Assim, no caso concreto, quando todas as alternativas terapêuticas previstas no respectivo PCDT já tiverem sido esgotadas ou forem inviáveis ao quadro clínico do paciente usuário do SUS, pelo princípio do art. 198, II, da CF, pode ser determinado judicialmente o fornecimento, pelo Sistema Único de Saúde, do fármaco, insumo ou procedimento não protocolizado.”

Há um claro prestígio às decisões adotadas pela Administração Pública em matéria de saúde e expressas nos PCDTs e DDTs, resguardando a possibilidade de concessão de tratamentos que estejam fora deles, apenas em hipóteses de clara demonstração de ausência de eficácia ou de esgotamento das opções no âmbito do SUS, o que, embora seja um avanço em relação à possibilidade indiscriminada de prolação de decisões judiciais fundadas, na grande maioria das vezes, no relatório de um único médico. 
Tais orientações coadunam-se, por sua vez, com a decisão proferida pelo Supremo Tribunal Federal na Arguição de Descumprimento de Preceito Fundamental-ADPF n. ${ }^{\circ}$ 47, na qual restou reconhecido que o direito subjetivo público à saúde:

“é assegurado mediante políticas sociais e econômicas, ou seja, não há um direito absoluto a todo e qualquer procedimento necessário para a proteção, promoção e recuperação da saúde, independentemente da existência de uma política pública que o concretize. Há um direito público subjetivo a políticas públicas que promovam, protejam e recuperem a saúde."

Para além da função de modificar a discussão do direito à saúde no âmbito da Justiça, a forma de elaboração dos Protocolos Clínicos e Diretrizes Terapêuticas serve de importante meio para busca da consensualidade administrativa, consoante será visto no tópico a seguir.

\section{O PROCEDIMENTO DE ELABORAÇÃO DE PROTOCOLOS CLÍNiCOS E DIRETRIZES TERAPÊUTICAS NO ÂMBITO DA CONITEC}

Consoante visto anteriormente, o processo de incorporação de novas tecnologias ao SUS desenvolve-se no âmbito da Comissão Nacional de Incorporação de Tecnologia do Ministério da Saúde, cuja composição é prevista no art.19 §1 da Lei n.12.401/2011, e no art. $7^{\circ}$ , do Decreto 7646/2011.

De acordo com o Decreto n. 7. 646/2011, o processo administrativo de incorporação de tecnologias em saúde pode ser deflagrado tanto por iniciativa do interessado (art. 15, I), o qual deve instruí-lo com documentação comprobatória da eficácia e segurança do produto, bem como de seu registro na ANVISA (art. 15, II, III), ou por iniciativa do próprio Ministério (art. $15 \S 4^{\circ}$ ), caso em que serão utilizadas as informações que ele dispõe. Sobre o produto, a seguir, a Secretaria Executiva da CONITEC realiza avaliação sobre a conformidade formal do pedido e da documentação (art. 16), passando à elaboração do relatório (art. 18). O parecer conclusivo do plenário é, então, submetido, pelo prazo de 20 (vinte) dias à Consulta Pública (art. 19), cujas contribuições retornam a referido órgão de apreciação ( art.20). A decisão final, por sua vez, cabe ao Secretário de Ciência, Tecnologia e Insumos Estratégicos do Ministério da Saúde, (art. 21), o qual pode, antes, solicitar a realização de audiência pública. O ato decisório é publicado no Diário Oficial da União. De tal decisão, cabe recurso sem efeito suspensivo 
(art.27) para a mesma autoridade, que, se vier a mantê-la, encaminha o processo para o Ministro de Estado da Saúde. Por fim, a partir da publicação da portaria aprovando o PCDT ou o DDT resultante do procedimento, os novos tratamentos deverão ser disponibilizados no prazo de 180 (cento e oitenta) dias ( art. 25).

Trata-se tal processo, daqueles de natureza ampliativa, de acordo com a classificação de MELLO (2005) ou seja, destinados à concessão (ou pelo menos análise dela) de algo por parte da Administração Pública, como, no caso, a aprovação de novo tratamento, tendo como princípios os elencados no art. $2^{\circ}$ da Lei n. 9.784/99. Quanto à estrutura e até mesmo aos prazos, há clara identificação com a Lei 9.784/99, cuja aplicação por analogia é, aliás, referida (art.28).

Deve-se chamar a atenção para o importante aspecto da obrigatoriedade de realização de consultas públicas, o que difere do tratamento do tema pela Lei n. 9.784/99, dependentes da avaliação de conveniência e oportunidade da Administração Pública, podendo-se afirmar que, no caso do procedimento de incorporação de novas tecnologias ao SUS , há a presunção, pela Administração Pública, de se estar diante de assunto de interesse geral, critério utilizado pela Lei n.9.732/97, em seu art.32, para justificar a realização de consulta pública.

Há de se ponderar, todavia, o fato de a realização das consultas públicas acontecer posteriormente à emissão do parecer conclusivo do plenário da CONITEC, cuja elaboração, portanto, não considera, de início, as importantes contribuições que podem ser dadas pelas sociedades médicas, das diversas especialidades, pela Academia, por organizações não governamentais, pelo cidadão.

Com efeito, ainda que as contribuições sigam para a manifestação do plenário, já terá este elaborado um prévio juízo de valor, de alguma forma diminuindo o peso das importantes contribuições da sociedade civil.

No tocante à decisão final sobre a incorporação ou não, remetendo o Decreto $\mathrm{n}$. 7.646/2011 para as disposições da Lei 9.784/99, deve-se entender pela possibilidade de interposição de recurso não apenas por aquele que deflagrou o processo de incorporação, mas também por terceiro interessado, nos termos de seu art. 58, II e IV que pode ser, decerto, pessoa natural ou jurídica que tenha oferecido contribuição por meio de Consulta Pública. 


\section{CONSENSUAlidade ADMinistrativa, Protocolos Clínicos E DIRETRIZES TERAPÊUTICAS}

A obrigatória abertura, mediante Consultas Públicas, do procedimento administrativo de aprovação dos PCDTs e DDTs à sociedade civil, implica importante forma de realização da consensulidade administrativa, sob a vertente de participação na construção das decisões estatais, ainda que tal desiderato pudesse ser implementado de forma mais intensa antes da elaboração do relatório.

Ou seja, em vez de adotar decisão unilateral e autoritária em matéria tão relevante, a Administração opta por incorporar a ela informações, dados, pontos de vista detidos por entidades ou pessoas dela distintas, conferindo maior legitimidade e credibilidade tanto ao processo quanto ao seu resultado.

No tocante à outra vertente da consensualidade administrativa, qual seja, a resolução de um conflito mediante a celebração de acordo entre a Administração e particulares para por fim a um dado conflito, pode-se colocar a questão sob a seguinte perspectiva:

Em primeiro lugar, a regular revisão dos tratamentos ofertados no âmbito do SUS, para as mais diversas especialidades, pode diminuir o grau de litigiosidade judicial em relação ao direito à saúde, quanto sendo realizada dentro de um procedimento que contempla os dados e informações trazidos por setores da sociedade civil, incorporando aquilo que, no atual estágio dos conhecimentos científicos, revele-se eficaz, efetivo, seguro e economicamente viável, com uma justificada relação custo/benefício, critério que precisa necessariamente ser considerado dentro de um sistema público de saúde,

Ou seja, quanto mais fortalecida a instância administrativa de discussão e decisão sobre aquilo que pode ser oferecido, dentro de um sistema público de saúde, regido pela integralidade, mas, também pela universalidade, onde escolhas precisam ser feitas, menos legitimidade terá o Poder Judiciário para nelas interferir e modificar o esquema de dado tratamento oferecido para todas as pessoas acometidas por dada enfermidade para assegurar outro diferente.

Tal fortalecimento, por sua vez, passa pela forma de escolha dos membros que irão compor a CONITEC e que, nos termos do art.19 \$ $1^{\circ}$ da Lei n.12.041/2011, cabe ao regulamento definir como será a composição, dela devendo fazer parte, necessariamente, um representante do Conselho Nacional de Saúde e um representante da especialidade na área, indicado pelo Conselho Federal de Medicina. 
A regulamentação do referido artigo veio a ser feita pelo art. $7^{\circ}$ do Decreto ${ }^{\circ} 7646 / 2011$, nos seguinte termos:

Art. 7o O Plenário da CONITEC é composto de treze membros, com "direito a voto, representantes dos seguintes órgãos e entidades, indicados pelos seus dirigentes:

I - do Ministério da Saúde:

a) Secretaria de Ciência, Tecnologia e Insumos Estratégicos do Ministério da Saúde, que o presidirá;

b) Secretaria-Executiva;

c) Secretaria Especial de Saúde Indígena;

d) Secretaria de Atenção à Saúde;

e) Secretaria de Vigilância em Saúde;

f) Secretaria de Gestão Estratégica e Participativa; e

g) Secretaria de Gestão do Trabalho e da Educação na Saúde;

II - da Agência Nacional de Saúde Suplementar - ANS;

III - da Agência Nacional de Vigilância Sanitária - ANVISA;

IV - do Conselho Nacional de Saúde - CNS

V - do Conselho Nacional de Secretários de Saúde - CONASS;

VI - do Conselho Nacional de Secretarias Municipais de Saúde - CONASEMS; e

VII - do Conselho Federal de Medicina - CFM, especialista na área

Não se observa, na referida composição, a participação, com direito a voto, de membro oriundo da Academia, a qual deveria estar oficialmente representada, ainda que o $\operatorname{art} .13^{\circ}$ preveja a possibilidade de convocação de representantes de entidades, autoridades, cientistas e técnicos nacionais e estrangeiros para colaboração e fornecimento de subsídios técnicos.

A respeito da indicação dos membros que irão compor a CONITEC, cujas escolhas pelos dirigentes dos diversos órgãos e entidades, seria essencial, no mínimo, a exigência de que elas recaíssem sobre profissionais que tenham expertise e condições para se manifestarem sobre os temas propostos, para que não haja simples homologação de uma decisão da Administração.

O fortalecimento da CONITEC deve passar por uma maior divulgação da sua atuação, bem como de incentivos à participação, nas consultas públicas por ela abertas, de entidades como as sociedades médicas das diversas especialidades, dos melhores pesquisadores do tema, de modo a não apenas assegurada formalmente a manifestação da sociedade civil, mas buscada sua efetiva contribuição para construção do consenso que representa uma um Protocolo Clínico ou uma Diretriz Diagnóstico Terapêutica. 
Ainda sobre a consensualidade, a instância administrativa pode ser incrementada com o desenvolvimento, em seu domínio do fórum próprio para discussão daqueles casos particulares em que tenha havido "perda da eficácia e surgimento de intolerância ou reação adversa relevante provocados pelo medicamento ou produto de primeira escolha", de acordo com o art.19-O da Lei n. $12.401 / 2011$.

Ou seja, em que casos podem ser adotados tratamentos diversos daqueles padronizados? Quais os critérios que devem estar presentes, tanto com relação ao impacto do tratamento alternativo proposto sobre a saúde do paciente, como, por exemplo, o aumento da expectativa de vida, ou a sobrevida livre de doença, o possível desenvolvimento de alguma toxicidade?

Em vez de tais decisões serem tomadas pelo Poder Judiciário, com embasamento, inclusive, no Enunciado n. 51 do Conselho Nacional de Justiça que considera viável a concessão de medicamento fora de hipótese prevista no protocolo clínico, quando as alternativas terapêuticas já tiverem sido esgotadas ou sejam impróprias para o quadro do paciente, a Administração Pública deve chamar para si as decisões sobre tais situações, quer viabilizando, quando for o caso, alguma outra forma de tratamento, quer fornecendo fundados elementos que mostrem a sua inviabilidade, quer terapêutica ou mesmo financeira, ao menos dentro do âmbito do SUS.

Importante considerar que o sistemático deslocamento, para o Judiciário, de decisões em matéria do direito à saúde, ainda que a propósito daquelas situações para as quais os esquemas terapêuticos contidos nos protocolos e diretrizes não tenham sido eficazes, enfraquece as discussões nas esferas participativas, bem como o referencial da saúde como um direito social, em favor da instância judicial e da busca de soluções individuais, consoante destaca ASENSI ( 2013).

Não se deve perder de vista que, com a anteriormente referida edição da Lei $n$. 13.140/15, sobre a mediação e a composição de conflitos no âmbito da Administração Pública, em seu art.32, III, § 3, que fomenta a tentativa de prevenção resolução deles por meio de câmaras a serem instauradas nos órgãos da Advocacia Pública, podem elas funcionar como canal para, juntamente com os órgãos deliberativos do SUS, ser apreciada a viabilidade ou não de concessão administrativa da pretensão do paciente.

Naturalmente, para tanto, precisam ser respeitadas as competências entre os entes federados em matéria de saúde, desenhadas pela Lei n.8080/90, que cria (é a lei que cria?)uma direção nacional do SUS, uma direção estadual e uma direção municipal, de acordo com seus arts. 
16, 17 e $18^{6}$. Vale destacar que estas vêm, contudo, sendo desconsideradas pelo Poder Judiciário, ao entender que as ações de saúde podem ser movidas, indistintamente, contra todos os entes, ou apenas contra um deles, dentro de uma perspectiva de solidariedade, citando-se como decisão paradigma, aquela proferida pelo STF no Recurso Extraordinário n. 566.471. ${ }^{7}$

Ou seja, na busca de solução consensual para aqueles casos em que os tratamentos previstos nos protocolos ou diretrizes revelaram-se ineficazes, há de considerar quem é o ente público encarregado por aquela prestação de saúde, de acordo com a distribuição de competências feita pela Lei 8.080/90, bem como aquele responsável pelo seu financiamento, de modo que possa ser estabelecido diálogo institucional, nas respectivas esferas governamentais, bem como entre elas, sobre a possibilidade, ou não, de fornecimento de alternativa terapêutica.

\section{CONCLUSÃO}

A consensualidade administrativa representa nova dimensão da atuação da Administração Pública, podendo ser observada sua expansão para diversos setores, dentro da perspectiva de que as decisões consensuais, além de usufruírem de maior legitimidade, concretizando o princípio democrático, são de observância tendencialmente mais fácil, tendo em vista a desnecessidade de recurso a meios autoritários.

A vertente objetiva do direito fundamental à saúde, no que concerne à organização e ao procedimento, identifica-se, na realidade brasileira, com o Sistema Único de Saúde- SUS, o qual, por sua vez, necessita definir quais são os tratamentos que, em relação às mais diversas enfermidades, serão oferecidos levando em consideração critérios como a eficácia, a segurança, a eficiência (relação custo/benefício) e a equidade..

Neste sentido, os Protocolos Clínicos e Diretrizes Terapêuticas cumprem o importantíssima função de oferecer bases seguras, atuais e economicamente viáveis às

\footnotetext{
${ }^{6}$ De acordo com a Lei 8.080/90 ( Lei do SUS) ,à direção nacional do SUS cabem atribuições como a fixação de padrões de referência de assistência à saúde para serviços estaduais e municipais ( art. 16, XI); a prestação de cooperação técnica e financeira aos Estados, ao Distrito Federal e aos Municípios ( art.16, XIII); a elaboração do Plano Nacional Estratégico no âmbito do SUS, em colaboração com os demais entes; o controle e a fiscalização de procedimentos, produtos e substâncias de interesse para a saúde (art.16, XII); a promoção da descentralização para as unidades federadas e para os Municípios dos serviços e ações de saúde ( art.16, XV). Já à direção estadual do SUS cabe a promoção da descentralização para os Municípios, além da execução supletiva de serviços de saúde. No âmbito municipal, por fim, tem-se a tarefa de gerir e executar os serviços públicos de saúde ( art.18, i). ${ }^{7}$ Julgadoem 18/11/2015, DJE 25/11/2015.
} 
prescrições médicas realizadas no SUS, bem como de assegurar a racionalização e sistematização da prestação dos serviços de saúde.

A importância dos PCDTs e DDTs aprovados pela Comissão Nacional de Incorporação de Tecnologias do Ministério da Saúde manifesta-se, também, diante do fenômeno da judicialização da saúde, servindo como parâmetro para que o Poder Judiciário observe, nas demandas propostas, o que é considerado adequado, viável e seguro pela Administração Pública. Este fato pode, se não impedir a discussão, em juízo, do direito à saúde, colocar a questão em outro patamar, representado pela necessidade de observância, ao menos, como ponto de partida, daquilo que tenha sido objeto do protocolo, conforme entendimento, inclusive, do Conselho Nacional de Justiça.

O processo administrativo de aprovação dos Protocolos Clínicos e Diretrizes Terapêuticas constitui importante meio para a realização da consensualidade administrativa, por ensejar a participação e a discussão da sociedade civil nas decisões sobre quais tratamentos devem deles constar. Ressalta-se que essa consensualidade pode ser incrementada com maior divulgação da realização de consultas públicas; com o oferecimento das contribuições externas antes da elaboração do parecer conclusivo; e, por fim, por meio de escolha de membros para compor a CONITEC que tenham domínio dos temas a serem discutidos, sendo de todo recomendável que, dentre eles, figure representante da Academia com direito a voto.

A consensualidade sob a vertente resolução de conflitos pode ser também construída mediante a discussão, na instância administrativa, dos casos em que os tratamentos previstos nos protocolos ou diretrizes não sejam eficazes ou não possam ser utilizados. Nesta circunstância, o que deve ser feito precisa atentar para as competências em matéria de saúde desenhadas pela legislação do SUS, estabelecendo o diálogo institucional entre os órgãos administrativos tanto da mesma esfera governamental quanto entre as entidades federativas, de modo a reafirmar a competência da Administração Pública para definir o que pode e deve ser disponibilizado por meio do sistema público de saúde.

\section{REFERÊNCIAS}

ASENSI, Felipe Dutra. Judicialização da saúde e Conselho Nacional de JustiçaPerspectivas e desafios. In DA SILVA, Ricardo Augusto Dias e NOBRE, Milton Augusto de 
Brito (coord.). $O C N J$ e os novos desafios da efetivação do direito à saúde. Belo Horizonte: Forum Editora, 2013. pgs.85-109.

BAUMAN. Zigmunt. O Amor Líquido. Sobre a fragilidade dos laços humanos. Rio de Janeiro: Zahar Editora, 2013.

BINENBOJM, Gustavo. Uma Teoria do Direito Administrativo. Rio de Janeiro: Renovar 2006.

CAÚLA, César. Judicialização da saúde- o que deve mudar em face da Lei ${ }^{\circ}$ 12.401/2011. In

In NETTO, Luísa Cristina Pinto e NETO, Eurico Bitencourt. Direito Administrativo e Direitos Fundamentais: diálogos necessários. Belo Horizonte: Editora Forum, 2012.

DE PALMA, Juliana Bonacorsi. Atuação administrativa consensual: estudos de acordos substitutivos no processo administrativo sancionador. Dissertação de Mestrado apresentada perante o Departamento de Direito do Estado da Universidade de São Paulo, 2010. www.teses.usp.br/teses/disponiveis/2/2134/tde-18112011-141226.

ESTORNINHO, Maria João. A Fuga para o Direito Privado. Coimbra: Almedina, 1999.

GADELHA. Maria Inês Pordeus. Escolhas públicas e Protocolos Clínicos- O orçamento, as renúncias necessárias e os novos projetos de lei. In DA SILVA, Ricardo Augusto Dias e NOBRE, Milton Augusto de Brito (coord.). $O C N J$ e os novos desafios da efetivação do direito à saúde. Belo Horizonte: Forum Editora, 2013, pgs.367-373.

HESSE, Konrad. Elementos de direito constitucional da República Federal da Alemanha, Porto Alegre, Sérgio Antônio Fabris Editor, 1998.

PEREIRA DA SILVA, Vasco Manuel Dias. Em Busca do Ato Administrativo Perdido. Coimbra: Almedina. 1999. 
MELLO, Celso Antônio Bandeira. Curso de Direito Administrativo. São Paulo: Malheiros, 2005.

NETTO, Luísa Cristina Pinto. Procedimentalização e Participação-Imposições jusfundamentais à atividade administrativa. In NETTO, Luísa Cristina Pinto e NETO, Eurico Bitencourt. Direito Administrativo e Direitos Fundamentais: diálogos necessários. Belo Horizonte: Editora Forum, 2012, pgs.215-242.

SARLET, Ingo Wolfgang. A Eficácia dos Direitos Fundamentais. Porto Alegre: Livrariado Advogado, 2003.

SARMENTO, DANIEL. Colisões entre Direitos Fundamentais e Interesses Públicos. In. GALDINO Flávio e SARMENTO Daniel (Org.) Direitos Fundamentais: estudos em homenagem ao professor Ricardo Lobo Torres. Rio de Janeiro: Renovar, 2006, pgs.269-329 